\title{
Como anda a infecção fúngica pela Candida na China?
}

Wu L, Feng J, Shi L, Shen X, Liu W, Zhou Z. Candidal infection in oral leukoplakia: a clinicopathologic study of 396 patients from eastern China. Ann Diagn Pathol. 2013 Feb; 17(1): 37-40. ISSN: 1079-2082.

Felipe Alan Romancini Graduando de Odontologia na FOL/Unimep

Desde a definição da leucoplasia como uma placa branca não raspável que clínica e histopatologicamente não se enquadra em qualquer tipo de doença, ela é considerada uma lesão precursora do câncer bucal com percentuais variáveis, segundo localização geográfica e hábitos utilizados. A candidíase, por sua vez, tem desencadeadores frequentes que promovem seu aparecimento como patogênico na mucosa bucal, principalmente quando há declínio imunológico. A associação de ambas, descrita na literatura como candidíase leucoplásica, é a infecção subsequente da leucoplasia pela Candida albicans e tem sido descrita como um fator de transformação maligno e sua influencia pode ser significativa para avaliação da etiologia de carcinomas na mucosa bucal.

Os critérios adotados para o diagnóstico da leucoplasia foram rigorosos e obedeceram às normas da Organização Mundial de Saúde (1997) e da leucoplasia com Candida pelo critério de Sitheeque-Samaranayake (2003). A faixa etária utilizada foi abrangente e as biópsias foram conclusivas da evidência, ou não, de infecção fúngica.

Avaliações sobre a prevalência e distribuição de candidíase raramente são mencionadas na literatura científica chinesa, registrando, assim, a importância do estudo em questão, quando a avaliação de 396 pacientes torna-se relevante. Os dados correspondem a uma avaliação que durou dois anos.
A partir dessas definições prévias, podese ter uma ideia e observar a correlação entre essas duas doenças. E é sobre esse assunto que o presente estudo trata, deixando pendentes as seguintes indagações: Qual a influência da candidíase sobre a leucoplasia? Pode haver risco de malignidade? Quem são seus principais "alvos"?

Estudos associados revelaram que a infecção por Candida está relacionada, majoritariamente, com a presença de displasia e neoplasia. As hifas de Candida podem ser vistas invadindo perpendicularmente o epitélio em sua superfície, de acordo com as amostras teciduais coradas pela hematoxilina e eosina e pelo PAS.

Os resultados foram esclarecedores para o grupo chinês: de 396 doentes, 59 (15,9\%) apresentaram leucoplasia com candidíase, variando as idades de 11 a 90 anos, com média de 60,7 anos, sendo 29 mulheres e 30 homens. As principais áreas afetadas foram a língua $(66,1 \%)$, seguida pela mucosa jugal $(20,3 \%)$. Casos de hiperplasia e displasia estiveram presentes respectivamente em $44,1 \%$ e $55,9 \%$ dos doentes.

Os resultados apontam, portanto, para uma verificação cuidadosa de lesões leucoplásicas. Como de consenso mundial, estas, além de hiperqueratósicas, são mais susceptíveis a displasias quando também estão comprometidas por Candida. 
A população de risco detectada? Pessoas acima de 60 anos de idade com leucoplasia principalmente na língua e aqueles cuja histopatologia revelou displasia nas lesões leucoplásicas.
Como tratar também é relevante nesse contexto, a leucoplasia com candidíase associada deve ser medicada com antifúngicos. Isso passou a ser protocolo no grupo estudado na China. 